Conclusions The NIP demonstrated appropriate prescribing practice. Patients and carers reported receiving medications more promptly and having doses adjusted when Out of Hours services were reluctant to do so. This provides evidence of the value of NIP training within the team.

\section{P-118 THE IMPACT AND DEVELOPMENT NEEDS OF INDEPENDENT NON-MEDICAL PRESCRIBERS IN CHILDREN'S HOSPICES}

Michael J Tatterton. Martin House Children's Hospice, Wetherby, UK

\subsection{6/bmjspcare-2018-hospiceabs. 143}

Background Non-medical prescribing (NMP) is well established within the British health service (Smith, Latter \& Blenkinsopp, 2014); NMPs in the UK have the most extensive prescribing rights of non-medical prescribers worldwide (Paterson, Redman, Unwin et al., 2016). Increasing numbers of NMPs are practicing within children's hospices (Tatterton, 2017) particularly in the community setting (Tatterton, 2018). Whilst writing the medicines management toolkit (Armitage, 2014), interest in prescribing from clinical and managerial perspectives increased.

Aim To explore the current context of non-medical prescribing in children's hospices in the UK, from the perspectives of prescribers and those who manage them; focusing on the challenges and benefits to children and families, practitioners themselves, their colleagues, and the employing organisation.

Method Internet-based questionnaires were sent to all 55 UK children's hospices, exploring the practice and context of prescribing of qualified and trainee prescribers, and service managers.

Results 20 children's hospices responded. Fourteen hospices employed a total of 39 NMPs. 50\% of NMPs prescribed to enable the continuation of existing medicines, $37.5 \%$ prescribed independently surrounding symptom management and control and $31.3 \%$ in end of life care. Perceived benefits of prescribing included timely access to medicines, increased efficiency and accuracy in the admissions process and medicines reconciliation and the increased ability to offer choice in the place of palliative and hospice care. Perceived barriers to prescribing surrounded opportunities to develop confidence, defining the scope of practice and the time required to assess, diagnose and treat.

Conclusion NMPs make a significant contribution to the prescribing workforce within children's hospices. The benefits of NMP are wide ranging, enhancing the experience of children, young people and their families, organisations and practitioners. To realise the benefits, the structures and processes that underpin prescribing need to be developed in order for practitioners to feel fully supported. This includes opportunities for peer support, specialist CPD opportunities that focus on the needs of paediatric life-limiting conditions, and better governance frameworks.

\section{P-119 ANTIBIOTIC STEWARDSHIP IN A HOSPICE ENVIRONMENT: AN AUDIT OF START SMART THEN FOCUS}

\footnotetext{
${ }^{1,2}$ Annelise Matthews, ${ }^{1}$ Aharani Kirupanadan, ${ }^{1}$ Roisin O'Dea, ${ }^{1}$ Tina Duttagupta, ${ }^{1}$ James Ferguson, 'Sumera Kayani. 'Sue Ryder St John's Hospice, Moggerhanger, UK; ${ }^{2}$ North West Anglia NHS Trust, Huntingdon, UK
}

10.1136/bmjspcare-2018-hospiceabs. 144
Background Antimicrobial stewardship is an important element of improving the safety and quality of patient care and reducing the emergence and spread of antimicrobial resistance. The Start Smart then Focus Toolkit was introduced to help NHS Trusts improve antibiotic stewardship (Public Health England,2018). Previous work has shown hospice patients are at high risk of infections due to frailty and immunocompromise. Furthermore there may be poor documentation of antibiotic prescribing (Donald \& Lindsay, 2014).

Aims To promote antibiotic stewardship by changing prescribing practice and introducing a sticker for antibiotic prescriptions.

Methods Two matched retrospective audits of hospice inpatients over one-month periods in July 2017 and February 2018. Notes were analysed for patients prescribed antibiotics and drug charts checked for review dates, stop dates, indications and signatures (Public Health England, 2018). The February 2018 notes were also checked to see if antibiotic stickers were used on the drug charts.

Results In February 2018, of the 30 inpatients, 16 were prescribed antibiotics, compared to 12 of 38 in July 2017. The original audit showed poor compliance with standards, with $50 \%(6 / 12)$ review dates, $75 \%(9 / 12)$ stop dates and 41\% (5/ 12) indications.

Correct prescribing increased with sticker use, with $100 \%$ (4/4) review dates, 50\% (2/4) stop dates and 100\% (4/4) indications compared to $17 \%(2 / 12)$ review dates, $0 \%(0 / 12)$ stop dates, and 75\% (9/12) indications in the February 2018 reaudit. However, there was poor sticker use with only four of 16 prescriptions on stickers.

Conclusions The stickers were an effective intervention for improving antibiotic stewardship, but one dependent on individual prescribers remembering to use them. In a hospice with continually changing junior staff, the best option may be to change the drug chart to have an antibiotic page to meet the Start Smart then Focus criteria. Further auditing could examine whether the hospice completes the Toolkit's Secondary Care Prescriber's Checklist (Public Health England, 2018).

\section{P-120 ANTICIPATORY PRESCRIBING IN LINCOLNSHIRE - A 21ST CENTURY APPROACH TO PATIENT-CENTRED CARE}

${ }^{1,2}$ Katharine Collett, ${ }^{2}$ Anna Chippendale, ${ }^{3}$ Jacqueline Rizan. ${ }^{1}$ St Barnabas Hospice, Lincolnshire, UK; ${ }^{2}$ United Lincolnshire Hospitals NHS Trust, Lincoln, UK; ${ }^{3}$ Lincolnshire Community Health Services NHS Trust, Lincoln, UK

\subsection{6/bmjspcare-2018-hospiceabs. 145}

Background For most people the greatest fear about dying is being in pain (ComRes, 2011; Parliamentary and Health Service Ombudsman, 2015). Anticipatory prescribing to aid prompt symptom management is well-established in end of life care (NICE, 2015). Lincolnshire has an established process for administering injectable medication in the community through a direction to administer (CD1) form completed by hand. Stakeholder feedback reported challenges with the existing system that limit pro-active, safe planning of symptom management for dying people. Lincolnshire's rural infra-structure means that arranging medication once a person develops symptoms is time consuming and causes delays in providing symptom relief.

Aims To redesign the CD1 form and associated processes to remove barriers for completion by prescribers, to provide clear guidance, and to facilitate safe administration of medications. Ultimately we want people in Lincolnshire to receive the right care at the right time. 